\title{
Laurent Mailhot, Plaisirs de la prose
}

\section{Simona Rossi}

\section{(2) OpenEdition}

\section{Journals}

\section{Edizione digitale}

URL: https://journals.openedition.org/studifrancesi/46419

DOI: 10.4000/studifrancesi.46419

ISSN: 2421-5856

\section{Editore}

Rosenberg \& Sellier

\section{Edizione cartacea}

Data di pubblicazione: 1 octobre 2007

Paginazione: 489-490

ISSN: 0039-2944

\section{Notizia bibliografica digitale}

Simona Rossi, «Laurent Mailhot, Plaisirs de la prose», Studi Francesi [Online], 152 (LI | II) | 2007, online dal 30 novembre 2015, consultato il 24 novembre 2021. URL: http://journals.openedition.org/ studifrancesi/46419; DOI: https://doi.org/10.4000/studifrancesi.46419

Questo documento è stato generato automaticamente il 24 novembre 2021.

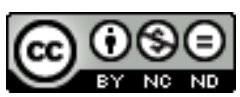

Studi Francesi è distribuita con Licenza Creative Commons Attribuzione - Non commerciale - Non opere derivate 4.0 Internazionale. 


\title{
Laurent Mailhot, Plaisirs de la prose
}

\author{
Simona Rossi
}

\section{NOTIZIA}

LAURENT MAILHOT, Plaisirs de la prose, Montréal, Les Presses de l'Université de Montréal, 2005, pp. 296.

1 Qual è l'elemento che accomuna le opere agli antipodi di Saint-Denis Garneau, di Gabrielle Roy, di Claire Martin, Gilles Marcotte, Gilles Archambault, Pierre Morency, Bernard Arcand e Serge Bouchard? In questo libro, vincitore del premio Études françaises 2005, Laurent Mailhot cerca per l'appunto di rispondere a questo quesito. Con uno stile che sa essere leggero ed efficiente al tempo stesso, egli accompagna il lettore sulla via del confronto di scritti molto diversi tra loro per genere, temi ed estetica, delineando un comune denominatore davvero d'eccezione: il piacere. Piacere di scrittura, prima di tutto, solitario e assoluto, che si esprime nella creazione di «un espace de la jouissance» (p. 13) tra il testo e il lettore; piacere rappresentato, raccontato, intuito o solo immaginato, talvolta persino atteso invano. Se, infatti, lo scrittore avverte necessariamente il bisogno di creare, e da questo trae soddisfazione, il piacere del lettore non è mai scontato. Ė vero che ci sono testi «de plaisir» (p. 13), che confortano e rasserenano, e «de jouissance» (p. 13), molto intensi dal punto di vista emotivo e per questo in grado di destabilizzare completamente il lettore, di far vacillare le sue certezze, ma accanto a essi troviamo anche quelli che lasciano indifferenti, che annoiano, che innervosiscono. Un libro può costituire un'arma, essere il fautore di una rivoluzione, di una vendetta, può rappresentare un grido di dolore e di denuncia. Mailhot vaglia ogni ipotesi, scandaglia minuziosamente, una a una, le opere di cui si occupa, dando libero sfogo a pensieri e ipotesi e dimostrando che i prosatori di cui parla, pur appartenendo a mondi ed epoche diversi, pur non conoscendosi, condividono incredibilmente lo stesso spazio creativo, lo stesso lavoro sulla lingua e sull'emozione. Il critico, così, diventa lui stesso prosatore. Si costruisce dunque un percorso di analisi letteraria al di fuori di ogni schema convenzionale, che mira dritto al cuore della narrazione e propone prospettive inedite e affascinanti, le quali 
rispondono senza alcun dubbio molto di più alla logica del sentire che delle «leggi» scientifiche. Del resto la prosa, spiega prontamente l'autore, non è solo un genere, è «une démarche, la recherche d'une voie entre les topiques et l'utopie, la conquête et la perte» (p. 296), è un mondo segreto e inesplorato che riserva, a colui che è pronto a riceverle, infinite sorprese. 